九州大学学術情報リポジトリ

Kyushu University Institutional Repository

\title{
Preferences for the Attributes of Household Kitchen Waste Source Separation Sertvices in China Using Latent Class Approach
}

Yuan, Yalin

Laboratory of Environmental Economics, Graduate School of Bioresource and Bioenvironmental Sciences, Kyushu University

Takahashi, Yoshifumi

Laboratory of Environmental Economics, Division of International Agricultural Resource Economics and Business Administration, Department of Agricultural and Resource Economics, Faculty of Agriculture, Kyushu University

Yabe, Mitsuyasu

Laboratory of Environmental Economics, Division of International Agricultural Resource Economics and Business Administration, Department of Agricultural and Resource Economics, Faculty of Agriculture, Kyushu University

https://doi.org/10.5109/1543422

出版情報：九州大学大学院農学研究院紀要. 60 (2)，pp.511-518，2015-09-18. Faculty of Agriculture, Kyushu University

バージョン :

権利関係 : 


\title{
Preferences for the Attributes of Household Kitchen Waste Source Separation Services in China Using Latent Class Approach
}

\author{
Yalin YUAN ${ }^{1}$, Yoshifumi TAKAHASHI and Mitsuyasu YABE* \\ Laboratory of Environmental Economics, Division of International Agricultural Resource Economics and \\ Business Administration, Department of Agricultural and Resource Economics, \\ Faculty of Agriculture, Kyushu University, Fukuoka 812-8581, Japan \\ (Received April 13, 2015 and accepted May 19, 2015)
}

\begin{abstract}
In this study, we conducted a hypothetical choice experiment in Beijing, China, to investigate residents' preferences for selected household kitchen waste source separation service attributes. A latent class approach was applied to observe heterogeneities among the respondents. The econometric analysis suggested that two segments of residents exist in the sample. Interestingly, $70.1 \%$ of the sample who were high educated, young, or respondents with more kitchen waste separation experience are more likely to accept the proposed separation services with frequent evening collection, while they do not show significant preferences for the attributes of instructor, container, and compensation. For the remaining (29.9\% of the sample) who were low educated, old, and with less kitchen waste separation experience, joining the separation program would impose a loss of utility. Moreover, they seem to prefer services with the attributes of frequent collection, plastic bags, and compensation. However, they do not show significant preferences for the attributes of time and instructor.
\end{abstract}

Key words: household kitchen waste; waste separation; choice experiment; latent segment model; Beijing; China

\section{INTRODUCTION}

Municipal solid waste is a growing problem in Beijing because of high urban population growth rates, rapid economic development, and consumption habits. Source separation of household waste is perhaps one of the best methods of managing waste (Tadesse, 2009). With kitchen waste comprising more than $60 \%$ of total municipal solid waste (Li et al., 2009; Qu et al., 2009), the local government has been undertaking kitchen-waste source separation campaigns since 2010. Free household kitchen waste containers are provided to each household, and instructors have been hired for each pilot community to help and supervise residents in the correct delivery of kitchen waste. Furthermore, residents can deliver their separated kitchen waste to the newly installed community kitchen-waste bins any time they want and without extra fees. By the end of 2012 , more than half $(2,412)$ of all the communities in Beijing were covered. However, limited progress was made (Deng et al., 2013; Nature, 2013).

The literature on household waste recycling in China has focused mainly on separation problems and methods (Deng et al., 2013; Huang et al., 2014; Tai et al., 2011; Yang et al., 2011; Zhou et al., 2014; Zhuang et al., 2008). Although residents' willingness to pay for a third party to separate their kitchen waste has been studied (Yuan \& Yabe, 2014a), little is known about residents' preferences, such as the attributes of waste separation services and the possibility that residential activities like waste

\footnotetext{
Laboratory of Environmental Economics, Graduate School of Bioresource and Bioenvironmental Sciences, Kyushu University, Fukuoka, Japan.

* Corresponding author (E-mail: yabe@agr.kyushu-u.ac.jp)
}

separation could be motivated by economic gain.

The heterogeneity of residents' service preferences and the influence of economic incentives on behaviour based on a choice experiment model have been widely studied around the world. Most of these studies, including Karousakis and Birol (2008), Czajkowski et al. (2014), Sakata (2007), Pek and Jamal (2011), Jin et al. (2006), and Yuan and Yabe (2014b), focus on the multinomial logit model. However, the multinomial logit model has always been criticized because heterogeneity among individuals is extremely difficult to examine (Louviere et al., 2000; Shen, 2006), even though this limitation could be relaxed to some extent by interaction terms between individual-specific characteristics and various choices. There is still a limit to this method because it requires a priori selection of key individual characteristics and attributes and involves only a limited selection of individual-specific variables (Boxall \& Adamowicz, 2002; Shen \& Saijo, 2009).

A latent class model is currently considered to provide the most powerful avenue for analysing heterogeneity (Colombo et al., 2009; Greene \& Hensher, 2003; Kamakura \& Wedel, 1999; Kontoleon \& Yabe, 2006). It can be used successfully to identify the sources of heterogeneity at the segment level. Investigation of heterogeneity at the segment level would be most relevant to policies when assessing the welfare impact of introducing a technology to different segments of the population (Kikulwe et al., 2011). Despite the potential usefulness of the latent class model for assessing the heterogeneity of residents' preferences for household waste management, it has so far not been used in China. There are, however, some applications of the latent class model on residents' preferences for waste management, such as the one undertaken in Poland (Czajkowski et al., 2014). 
Furthermore, household-level separation is inconvenient for households because it requires space, time, and effort (Czajkowski et al., 2014; Karousakis \& Birol, 2008; Laurent et al., 2013; Victor et al., 2013). Therefore, this study employed a stated-preference choice experiment method to shed light on residents' evaluations via the households' willingness to accept compensation for their participation in source separation of household kitchen waste in Beijing City. Moreover, in order to investigate the differences in preference for sorting household kitchen waste at home and to detect the level of heterogeneity of residents' preferences for household kitchen waste separation services and the specified service attributes, we estimated the latent class model.

This paper proceeds as follows: the theoretical basis of the economic models used in this study is discussed in the next section, and the questionnaire design and data collection methods are explained in section three. The model results are presented and interpreted in section four. Discussion and conclusions are included in section five and section six, separately.

\section{MATERIALS AND METHODS}

\section{The Latent Class Model}

The latent class model was developed by Swait (1994), and it is based on the conceptual framework developed in the works of McFadden et al. (1986) and Ben Akiva et al. (2002). Recently, the latent class model has been applied in various areas, such as agricultural technologies and foodstuffs (Birol et al., 2009; Hu et al., 2004; Kikulwe et al., 2011; Kontoleon \& Yabe, 2006), household appliances (Shen \& Saijo, 2009), public organization services (Fonseca, 2009), and wetland management (Birol et al., 2006).

Sources of preference heterogeneity can be identified by the latent class model by detecting several latent classes of respondents that are characterized by relatively common tastes. The utility in the latent class model that respondent $i$ belongs to segment $s$, which is derived from choosing service alternative $\in C$, can be written as:

$$
U_{i j \mid s}=\beta_{s} X_{i j}+\varepsilon_{i j \mid s}
$$

where $X_{i j}$ is a vector of attributes associated with service alternative $j$ and respondent $i$, and $\beta_{s}$ is a segment-specific vector of parameters. The heterogeneity in service attribute preferences across segments is captured by the differences of the vector $\beta_{s}(s=1,2, \ldots S)$. Assuming that the error term $\varepsilon_{i j \mid s}$ is identically and independently distributed (IID) and that it follows a Gumbel distribution, Equation (2) shows the probability of alternative $j$ being chosen by the $i$ th individual in segment $s$.

$$
P_{i j \mid s}=\exp \left(\beta_{s} X_{i j}\right) / \sum_{h=1}^{c} \exp \left(\beta_{s} X_{i h}\right)
$$

Next, $M^{*}$ stands for a segment membership likelihood function that sorts the respondents into one of the $S$ finite number of latent classes with a probability, $P_{i s}$. Therefore, the membership likelihood function for respondent $i$ and segment $s$ can be given as $M_{i s}^{*}=\gamma Z_{i}+$ $\delta_{i s}$, where $Z$ is the observed characteristics of the respondent, such as demographic characteristics. Assuming that the error term $\delta_{i s}$ in the respondent membership likelihood function is IID among respondents and segments, and following the Gumbel distribution, we can express the probability that respondent $i$ belongs to segment $s$ as:

$$
P_{i s}=\exp \left(\gamma_{s} Z_{i}\right) / \sum_{k=1}^{s} \exp \left(\gamma_{k} Z_{i}\right)
$$

where $\gamma_{k}(k=1,2, \ldots, \mathrm{S})$ are the parameters of segment specific to be estimated. This means that the various respondent characteristics contribute to the probability of segment membership. A positive (or negative) and significant $\gamma$ indicates that the associated respondent characteristic, $Z_{i}$, increases (or decreases) the probability that respondent $i$ belongs to segment $s$, and $P_{i s}$ sums to one across the $\mathrm{S}$ latent segments, where $0 \leq P_{\text {is }} \leq 1$.

Combining the conditional choice Equation (2) and the membership classification Equation (3), we can construct a mixed logit model that simultaneously accounts for service choice and segment membership. Equation (4) (Kontoleon \& Yabe, 2006) shows the joint unconditional probability of individual $i$ belonging to segment $s$ and choosing service alternative $j$.

$$
\begin{aligned}
P_{i j s}= & \left(P_{i j \mid s}\right) \times\left(P_{i s}\right)=\left[\exp \left(\beta_{s} X_{i j}\right) / \sum_{h=1}^{c} \exp \left(\beta_{s} X_{i h}\right)\right] \times \\
& {\left[\exp \left(\gamma_{s} Z_{i}\right) / \sum_{k=1}^{s} \exp \left(\gamma_{k} Z_{i}\right)\right] }
\end{aligned}
$$

There are various statistical criteria for deciding on the optimal number of latent segments (Andrews \& Currim, 2003; Boxall \& Adamowicz, 2002; Greene \& Hensher, 2003; Kamakura \& Wedel, 1999; Louviere et al., 2000; Morey et al., 2006; Shen, 2006; Swait, 2007). In this study, we employed three criteria: the $\rho^{2}$, Bozdogan Akaike Information Criterion (AIC3), and Bayesian Information Criterion (BIC). They are defined as:

$$
\begin{aligned}
& \rho^{2}=1-L L_{s} / L L_{0} \\
& A I C 3=-2 L L_{s}+3 P \\
& B I C=-L L_{s}+\left(\frac{P}{2}\right) \times \ln (N)
\end{aligned}
$$

where $L L_{s}$ is the log likelihood at convergence with $s$ classes, $P$ is the number of parameters in the model with $s$ classes, $L L_{0}$ is the log likelihood of the sample with equal choice probabilities, and $\mathrm{N}$ is the sample size.

\section{Choice Experiment Design}

A number of important attributes of separation services have been recognized by González-Torre and Adenso (2005), Sakata (2007), Karousakis and Birol (2008), Gallardo, et al. (2010), and Czajkowski et al. (2014), such as walking distance, collection frequency, number of separations, educational programs, and incentives. This study focuses on an improved household kitchen waste 
Table 1. Attributes and their levels of household kitchen waste separation services used in the choice experiment study

\begin{tabular}{lcl}
\hline \multicolumn{1}{c}{ Attribute } & Levels & \multicolumn{1}{c}{ Description } \\
\hline 1. Frequency & 2 & Once per day; Twice per week \\
2. Time & 2 & Morning; Evening \\
3. Instructor & 2 & Need; No need \\
4. Container & 2 & Plastic bag; Barrel \\
5. Compensation (CNY/month/household) & 4 & $1 ; 5 ; 8 ; 10$ \\
\hline
\end{tabular}

${ }^{\mathrm{a}} \mathrm{CNY}=$ Chinese Yuan, $1000 \mathrm{CNY}=\mathrm{US} \$ 161.5$ as of July, 2013 currency exchange rate.

separation system. The current program places community kitchen-waste bins as the traditional mixed-garbage bins, which are placed in front of residential apartment buildings. In other words, the distance between containers and residents is short. Therefore, this study focuses only on the service attributes of delivery and collection frequency, collection time, and cash and non-cash incentives. Instructors in the current collection system provide separation information to residents. Cash is presented as a compensation and non-cash incentives such as free household kitchen-waste containers are also provided. The proposed attributes and their levels are listed in Table 1. For the levels of compensation, four levels were first designed, based on the current household waste cleaning fee in Beijing, which is 3 Chinese Yuan (CNY) (US\$0.48) per household per month, and then tested and adjusted by the pretested survey. Finally, four levels, 1 CNY (US\$0.16), 5 CNY (US\$0.81), 8 CNY (US\$1.29), and $10 \mathrm{CNY}$ (US\$1.62) per household per month, were used.

Therefore, based on these four two-level-attributes and one four-level-attribute, 16 pair-wise comparisons of alternative collection services were achieved from 64 $\left(2^{4} \times 4\right)$ combinations using experimental design techniques (Louviere et al., 2000) with SPSS conjoint software. These were randomly blocked into five different versions, each with three, three, three, three, and four choice sets. As Figure 1 shows, each set contains two collection service profiles (Option A and B) and an option to 'opt out' by selecting neither one (Option C), in which case the respondents were told that collection services would not be provided. Such an 'opt out' option can be considered as a status quo or baseline alternative, the inclusion of which in the choice set is instrumental to achieving welfare measures that are consistent with demand theory (Bateman et al., 2003; Bennett \& Blamey, 2001; Louviere et al., 2000). Respondents were required to choose one of the three options.

Furthermore, before the choice experiment question, information regarding the residents' knowledge and awareness of the environment as well as their current household situation regarding kitchen waste generation and separation were posed. In addition, socio-economic characteristics of the respondents were collected at the end of the questionnaire.

\section{Data Collection}

Many European countries (Husaini et al., 2007; Jacobsen et al., 2002) have made great strides in household waste recycling via the offering of economic incentives. In order to know how residential behaviour change is related to economic persuasion in China, we conducted a case study in the central urban area of Beijing, which includes six districts: Xicheng, Dongcheng, Haidian, Chaoyang, Fengtai, and Shijingshan (Figure 2). Firstly, Dongcheng and Haidian districts were selected among the six districts via purposive sampling techniques. Next, a total of 12 pilot communities were randomly selected from the 651 pilot communities of these two selected districts. Finally, respondents were selected randomly and interviewed face-to-face at different times of the day.

This survey took about 40 days from June 20 to the beginning of August, 2013. A pilot survey took place dur-

To ensure the quantity and quality of kitchen waste sent to the compost system and high levels public participation, here the compost company would like to change the current service values and provide relevant compensation for these changes. Some detailed service attributes are listed as follows. Please compare the choice sets carefully and then choose one $(V)$ :

\begin{tabular}{|c|c|c|c|}
\hline Attribute & Option A & Option B & Option C \\
\hline Frequency & 2/week & 1/day & \multirow{5}{*}{$\begin{array}{l}\text { Neither service A nor B: I do } \\
\text { not wish to participate in this } \\
\text { kitchen waste separation } \\
\text { program. }\end{array}$} \\
\hline Time & Evening & Morning & \\
\hline Instructor & Need & No need & \\
\hline Container & Barrel & Plastic bag & \\
\hline Compensation (CNY per household per month) & 10 & 1 & \\
\hline Which option do you prefer? (tick only one) & & & \\
\hline
\end{tabular}

Fig. 1. Example of a household kitchen waste separation service choice set. 


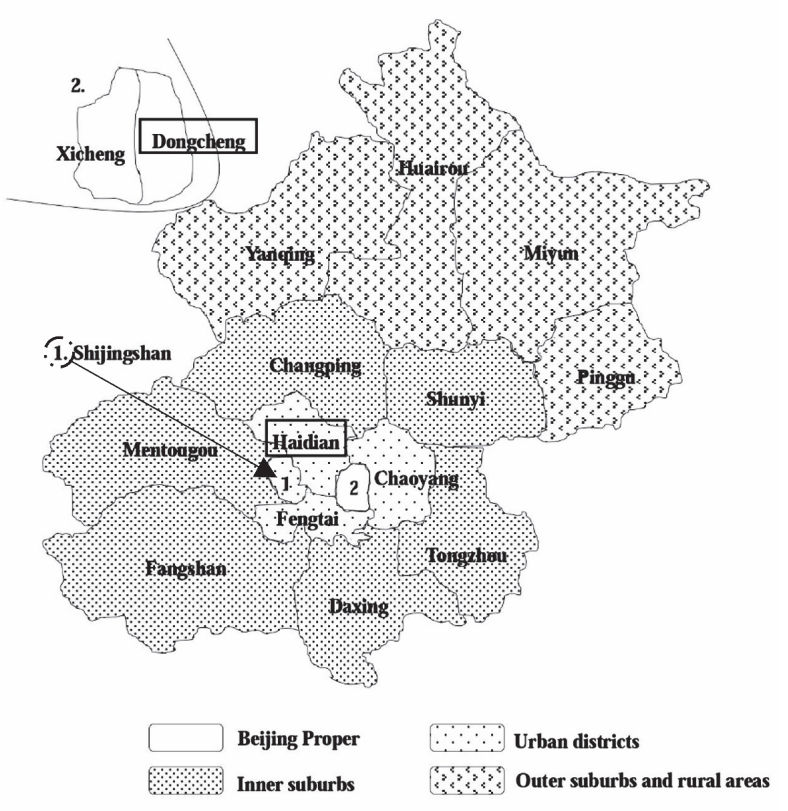

Fig. 2. Beijing map and survey area

ing the first week to test the questionnaire. Finally, each respondent was randomly presented with one of the five versions of the revised questionnaire. In total, 401 respondents were approached, and 394 of them provided valid responses (98.3\% of the respondents).

The main socioeconomic information of the respondents and the statistics (Beijing Statistic Yearbook, 2013) are shown in Table 2. The reason for the higher percentage of women (58\%) compared to the average (50\%) is probably due to the difficulty of interviewing men, who are at work during the daytime. The education distribution in the samples was approximately $42 \%$ for respondents with a high level of education, which is higher than the statistical level (32\%). This high percentage may be a result of the fact that the survey focused on the central urban area of Beijing, which has a high concentration of highly educated citizens. The majority of the respondents (57.4\%) were between the ages of 30 and 59 and have three family members $(34.5 \%)$. To detect residents' satisfaction with their family income, three levels of income, low, medium, and high, were presented to the respondents. Approximately half of the respondents (49.5\%) reported their family economic level in Beijing city as being in the middle range. Over $70 \%$ of the respondents said they have little or no kitchen waste separation experience. $67.3 \%$ of the sample were from Haidian district, and each version of the questionnaire has an almost equal sample size of approximately 79.

\section{RESULTS}

\section{Results of the Latent Class Model}

In the choice model analysis, the utility functions depicted in Equation (4) are econometrically estimated using latent class regression with the software package TSP 5.1. After experimentation with various specifications for the segment membership component, the best fit specification was to include the service attributes and the three socioeconomic characteristics of education, age, and separation experience ${ }^{1}$. Table 3 shows the data coding.

Determination of the optimal numbers of segments requires a balanced assessment of $\rho^{2}$, AIC3, and BIC, as

Table 2. Socioeconomic information of the sample and statistics

\begin{tabular}{|c|c|c|c|c|c|c|c|c|c|}
\hline Category & Levels & Freq. & $\%$ & $\%^{\mathrm{a}}$ & Category & Levels & Freq. & $\%$ & $\%^{\mathrm{a}}$ \\
\hline \multirow{2}{*}{ Sex } & Male & 166 & 42.1 & 50 & \multirow{3}{*}{$\begin{array}{l}\text { Economic } \\
\text { level }\end{array}$} & Low & 128 & 32.5 & \\
\hline & Female & 228 & 57.9 & 50 & & Middle & 195 & 49.5 & \\
\hline \multirow{3}{*}{ Education } & No high school & 125 & 31.7 & 44 & & High & 71 & 18 & \\
\hline & High school or equivalent & 103 & 26.1 & 22 & \multirow{2}{*}{ Separation } & Always or most times & 115 & 29.2 & \\
\hline & College or above & 166 & 42.1 & 32 & & Otherwise & 279 & 70.8 & \\
\hline \multirow{3}{*}{$\begin{array}{l}\text { Age } \\
\text { (in years) }\end{array}$} & $29 \geq$ & 66 & 16.7 & 38 & \multirow{2}{*}{ District } & Haidian & 265 & 67.3 & 79 \\
\hline & $30-59$ & 226 & 57.4 & 48 & & Dongcheng & 129 & 32.7 & 21 \\
\hline & $60 \leq$ & 102 & 25.8 & 14 & \multirow{5}{*}{ Version } & 1 & 79 & 20.1 & \\
\hline \multirow{5}{*}{$\begin{array}{l}\text { Household } \\
\text { size } \\
\text { (in persons) }\end{array}$} & 1 & 26 & 6.6 & 22 & & 2 & 79 & 20.1 & \\
\hline & 2 & 70 & 17.8 & 31 & & 3 & 79 & 20.1 & \\
\hline & 3 & 136 & 34.5 & 31 & & 4 & 80 & 20.3 & \\
\hline & 4 & 76 & 19.3 & 9 & & 5 & 77 & 19.5 & \\
\hline & $5 \leq$ & 86 & 21.8 & 7 & \multicolumn{2}{|l|}{ Total } & 394 & 100 & 100 \\
\hline
\end{tabular}

a Stands for the column of the data are based on the Beijing Statistic Yearbook (2013).

\footnotetext{
${ }^{1}$ Note that the variables associated with household economical level, household size, location, and so on, are not listed in the Table 3 because these socioeconomic characteristics are not significant even at a $10 \%$ significance level in any of the cases.
} 
Table 3. Variables included in the latent class model and coding of levels

\begin{tabular}{ll}
\hline \multicolumn{1}{c}{ Parameter } & \multicolumn{1}{c}{ Levels and coding } \\
\hline Services attributes & \\
\hline $\begin{array}{l}\text { Frequency } \\
\text { Time }\end{array}$ & $\begin{array}{l}\text { Once per day }=1 \text {; Twice per week }=-1 \\
\text { Evening }=1 ; \text { Morning }=-1\end{array}$ \\
Instructor & Need $=1$; No need $=-1$ \\
Container & Plastic bag $=1 ;$ Barrel $=-1$ \\
Compensation (CNY per month per household) & $1,5,8,10$ \\
\hline Socioeconomic characteristics & \\
\hline Education & College or above $=1 ;$ Otherwise $=-1$ \\
Middle age & $30-59$ years old $=1 ;$ Otherwise $=-1$ \\
Old age & Over 60 years old $=1$; Otherwise $=-1$ \\
Separation & Always or most time $=1 ;$ Otherwise $=-1$ \\
\hline
\end{tabular}

Table 4. Latent segment models and criteria for determining the best fit number of segments

\begin{tabular}{cccccc}
\hline $\begin{array}{c}\text { Number of } \\
\text { segments }\end{array}$ & $\begin{array}{c}\text { Number of parameters } \\
(\mathrm{P})\end{array}$ & $\begin{array}{c}\text { Log likelihood } \\
(\mathrm{LL})\end{array}$ & $\rho^{2}$ & AIC3 & BIC \\
\hline 1 & 6 & -1289.46 & 0.065 & 2596.92 & 1307.39 \\
2 & 17 & -1229.50 & 0.108 & 2510.00 & 1280.30 \\
3 & 28 & -1211.50 & 0.121 & 2507.00 & 1295.17 \\
4 & 39 & -1195.34 & 0.133 & 2507.68 & 1311.88 \\
\hline
\end{tabular}

a Sample size is 1259 choices from 394 individuals (N)

${ }^{\mathrm{b}}$ AIC3 = Bozdogan's Akaike Information Criterion, BIC = Bayesian Information Criterion.

reported in Table 4. The optimal number of segments is reached when additional segments provide little extra information or are simply superfluous. The model introduced in Section two is estimated for up to four segments. The $\rho^{2}$ increases as more segments are added. The AIC3 and BIC are minimized at the three-segment and two-segment models, respectively. However, marginal improvement diminishes after the two-segment model, indicating that a model with two segments is the optimal solution in this empirical application.

Results of segment membership for the two-segment latent class model are reported in Table 5. The parameters for the first class were normalized to 0 , permitting us to identify the remaining coefficients of the model.

It can be seen that respondents in the latent segment two are characterized mainly by a low education level, older age, and a lack of kitchen waste separation experiences. Moreover, we found that the effect of older age on determining segment membership was larger than that of other attributes, since the estimated parameters of older age were approximately 8.8 times bigger than that of higher education level. The remaining respondents in our survey are classified as latent segment one. The membership coefficients for Segment one can be implicitly interpreted by comparison with the signs of the statistically significant parameters estimated for the segment two (Boxall \& Adamowicz, 2002). Therefore, respondents with a higher education level, young age, or who have had more separation experience are statistically more likely to belong to the latent segment one.

The estimated utility function parameters of the two-segment model are listed in Table 5 from columns four to seven. In order to compare with the utility function of the two-segment model, we first estimated the utility function for the one-segment model (the standard logit model). As shown in the second to the third columns of Table 5, the one-segment model results indicate that the attributes of frequency, time, and container contribute to utility (respondents prefer a service with frequent evening collection and plastic bags), whereas the attribute of instructor does not. In addition, the results suggest that none of the respondents were incentivized by compensation to accept the services. Evidently, this one-segment finding contrasts the two-segment model.

For the two-segment model, the utility coefficients show that different tested attributes determine household kitchen waste service choice for both segments. In terms of frequency, as expected, residents in both segments prefer the once-per-day over the twice-per-week attribute level, whereas the provision of an instructor did not show significance. Moreover, the attributes time and container of the impact on utility (significant or insignificant) differ between the two segments. Contrary to economic theory, only members in the Segment two prefer services with compensation. The probable reason is that the level of compensation is too low, compared to the 
Table 5. Parameter estimates from the latent class model

\begin{tabular}{|c|c|c|c|c|c|c|}
\hline \multirow{3}{*}{ Parameter } & \multirow{2}{*}{\multicolumn{2}{|c|}{ One-segment }} & \multicolumn{4}{|c|}{ Two-segment } \\
\hline & & & \multicolumn{2}{|c|}{ Segment one } & \multicolumn{2}{|c|}{ Segment two } \\
\hline & Coeff. & S.E. & Coeff. & S.E. & Coeff. & S.E. \\
\hline \multicolumn{7}{|c|}{ Estimated coefficients of the class membership function } \\
\hline Constant & & & 0 & (fixed) & 0.178 & 3.977 \\
\hline Education & & & 0 & (fixed) & $-1.038 * *$ & 0.444 \\
\hline Middle age & & & 0 & (fixed) & $7.446^{*}$ & 4.345 \\
\hline Old age & & & 0 & (fixed) & $9.004^{* *}$ & 4.529 \\
\hline Separation & & & 0 & (fixed) & $-3.665^{*}$ & 2.092 \\
\hline \multicolumn{7}{|c|}{ Estimated coefficients of the utility function } \\
\hline ASC & 0.092 & 0.104 & $0.695^{* * *}$ & 0.137 & $-2.812 * *$ & 1.043 \\
\hline Frequency & $0.567^{* * *}$ & 0.046 & $0.522 * * *$ & 0.057 & $1.367^{* * *}$ & 0.404 \\
\hline Time & $0.109 * *$ & 0.044 & $0.169 * * *$ & 0.054 & -0.128 & 0.162 \\
\hline Instructor & -0.056 & 0.044 & -0.050 & 0.052 & -0.048 & 0.152 \\
\hline Container & $0.112^{* *}$ & 0.044 & 0.035 & 0.054 & $0.908^{* *}$ & 0.342 \\
\hline Compensation & 0.008 & 0.013 & 0.009 & 0.016 & $0.169^{*}$ & 0.102 \\
\hline Share & & & \multicolumn{2}{|c|}{$70.10 \%$} & \multicolumn{2}{|c|}{$29.90 \%$} \\
\hline
\end{tabular}

urban average personal monthly income (3,425 CNY, approximately US\$553.14) (Beijing Statistics Yearbook, 2013). For respondents in Segment one, the alternative specific constant is positive and significant, indicating that these residents prefer the presented services (A or B) over the status quo. For respondents in Segment two, however, the alternative specific constant is negative and significant, indicating that the members of this segment prefer the status quo.

For respondents in Segment one, the utility coefficients reveal that the most important attribute is frequency (once per day), followed by time (evening), whereas, instructor, container, and compensation did not show a significant influence on the respondents' choices. Similarly, the attribute of frequency has the largest absolute size in the Segment two, indicating that this attribute is the most important determinant of household kitchen waste separation service choice, followed by the attributes of container and compensation. Both the container and compensation attributes exhibit positive signs, which reveals that residents in this segment prefer services with plastic bags and more compensation, whereas they did not show a significant preference for time and instructor.

The probability that a randomly chosen respondent belongs to a given segment can be calculated by inserting the estimated segment socioeconomic coefficients into Equation (3). Using this procedure, we estimated the probability that the $i$ th individual belongs to each of the two segments, and found the relative share of sample based on the sum of probability of $n$ individuals are $70.1 \%$ and $29.9 \%$, respectively.

Hence, it appears that respondents who are young, highly educated, or have separation experience (70.1\% of the sample) and a positive attitude toward the proposed program prefer services with frequent evening collection more, whereas the remaining respondents (29.9\% of the sample) who are older, with a lower education level and less separation experience have a rather negative predisposition towards the proposed household kitchen waste source separation services. The latter prefer services with a once-per-day collection frequency, accompanied by plastic bags and more compensation.

\section{Marginal Willingness to Accept Estimates}

From Table 5, we can estimate the marginal willingness to accept (MWTA) compensation for the significant variables in Segment two. The calculations of MWTA compensation are based on the one provided by $\mathrm{Hu}$ et al. (2004). The Equation is as follows:

$$
\text { MWTA Compensation }=-2 \times\left[\beta_{\text {Attribute }} / \beta_{\mathrm{C}}\right.
$$

Therefore, the MWTA compensation for the attributes of frequency and container are approximately $-16.18 \mathrm{CNY}$ (US\$-2.61) and -10.75 CNY (US\$-1.74), with 95\% confidence intervals (Hanemann \& Kanninen, 1999), between -28.52 CHY (US\$-4.60) and -3.85 CHY (US\$-0.61), and between -17.61 CHY (US\$-2.84) and -3.89 CHY (US\$$0.63)$, respectively. This means that older respondents with a low level of education have a marginal willingness to pay approximately US $\$ 2.61$ when the frequency 
attribute changes from twice per week to once per day, and US $\$ 1.74$ when the container attribute changes from barrel to plastic bag.

\section{DISCUSSION}

Rapid population growth, urbanization, industrialization, and economic development have resulted in the generation of an enormous volume of solid waste in residential areas throughout the world. Since 2010, Beijing authorities have been launching kitchen waste separation programs and making great efforts to obtain the cooperation of residents by encouraging them to source separate kitchen waste. However, little progress has been made. In this study, a choice experiment was used to investigate residents' preferences for selected household kitchen waste source separation service attributes (frequency, time, container, instructor, and compensation). A total of 394 residents from the Haidian and Dongcheng districts of Beijing city were involved. A latent class model was constructed to capture the heterogeneity in residents' preferences for household kitchen waste source separation service attributes and to profile residents who are more or less likely to conduct kitchen waste source separation.

A previous study of Beijing residents' attitudes towards household kitchen waste separation (Yuan \& Yabe, 2014a) concluded that approximately $41.4 \%$ of the respondents preferred to pay for a third party to sort kitchen waste rather than doing it themselves, whereas $31.0 \%$ preferred to sort kitchen waste themselves, and the remaining $27.6 \%$ refused to pay or to sort the waste themselves. In this study, we show that there are two distinct and coherent segments of residents. A significant group of respondents, who are young, high educated, or have more kitchen waste separation experiences (Segment one), prefer the proposed self-separation services over the status quo; however, the remaining subset of respondents (Segment two), who are old, low educated, and have less kitchen waste separation experiences, derive negative utility from kitchen-waste sorting. Furthermore, the results show that the Segment one respondents prefers systems with frequent collections occurring in the evenings. Despite the time and effort involved in home sorting, these respondents do not show a significant preference for compensation, instructor, or free container. In line with the findings of Yuan and Yabe (2014a), the membership of this segment is linked to their high education level and young age, and their existing sorting behaviour also shows significant influence on their positive attitudes.

Members in Segment two would need to be not only compensated, but also provided with free environmentally friendly plastic bags and frequent collection service. However, they did not show a significant preference for the attributes of time and instructor. These people are characterized by a low education level, older age, and less separation experiences.

In conclusion, these results suggest a potential for improvement in the source separation program in Beijing.
Frequency does have a significant effect on the choice of household kitchen waste separation services, possibly because the odor and decaying characteristic of kitchen waste make keeping kitchen waste inside the home difficult, especially in the summer. Furthermore, our findings show little interest among both segments in the presence of a kitchen-waste-separation instructor. Therefore, it might be worthwhile for the local government to reconsider investing in instructors. Moreover, our results indicate that more conveniences (e.g., frequent collection) should be provided to communities formed by a high percentage of highly educated, younger residents, whereas not only conveniences but also cash and non-cash compensations, such as free plastic bags, should be provided to communities that have a high percentage of older residents with a low level of education.

Although this study reveals insight into MWTA compensation, it should be noted that the majority of the respondents did not show a significant preference for compensation when it comes to household kitchen waste separation behaviour, which seems to contradict economic theory. The probable reason is the small value of the provided compensation. Therefore, future research can increase the level of compensation value to estimate the MWTA compensation level for the majority of residents. Moreover, the data that was available does not allow us to identify seasonal differences in residents' preferences for services attributes, which could be a potential area for further research in the field of household kitchen waste separation.

\section{ACKNOWLEDGMENTS}

The authors would like to acknowledge the help during data collection from Ms. Xiaohui CHEN who works at the community service centre of Yuhaiyuanwuli and the advice, comments, and suggestions from members of the Laboratory of Environmental Economics, Kyushu University, Japan. Yalin YUAN is sponsored by the China Scholarship Council under Grant [number 2011630098]. This work was supported by JSPS KAKENHI Grant Number 26310311.

\section{REFERENCES}

Andrews, R. L., I. S. Currim 2003 A comparison of segment retention criteria for finite mixture logit models. Journal of Marketing Research 40: 235-243

Bateman, I., R. T. Carson, B. Day, W. M. Hanemann, N. Hanley, T. Hett, M. Lee, G. Loomes, S. Mourato, E. Ozdemiroglu 2003 Guidelines for the use of stated preference techniques for the valuation of preferences for non-market goods. Edward Elgar, Cheltenham, UK

Beijing Municipal Bureau of Statistics:Beijing, R.o.C. 2013 Beijng Statistical Yearbook

Moshe, B., W. Joan, B. Adriana, G. Dinesh, M. Taka, P. Amalia 2002 Integration of choice and latent variable models. Perpetual motion: Travel behaviour research opportunities and application challenges, 431-470

Bennett, J., R. Blamey 2001 The choice modelling approach to environmental valuation. Edward Elgar Publishing, UK

Birol, E., K. Karousakis, P. Koundouri 2006 Using a choice experiment to account for preference heterogeneity in wetland 
attributes: The case of Cheimaditida wetland in Greece. Ecological Economics 60: 145-156

Birol, E., E. R. Villalba, M. Smale 2009 Farmer preferences for milpa diversity and genetically modified maize in Mexico: A latent class approach. Environment and Development Economics 14: 521

Boxall, P. C., W. L. Adamowicz 2002 Understanding heterogeneous preferences in random utility models: A latent class approach. Environmental and Resource Economics 23: 421-446

Colombo, S., N. Hanley, J. Louviere 2009 Modeling preference heterogeneity in stated choice data: An analysis for public goods generated by agriculture. Agricultural Economics 40: 307322

Czajkowski, M., T. Kądziela, N. Hanley 2014 We want to sort! Assessing households' preferences for sorting waste. Resource and Energy Economics 36: 290-306

Deng, J., W. Xu, C. Zhou 2013 Investigation of waste classification and collection actual effect and the study of long acting management in the community of Beijing. Environmental Science, 395-400

Fonseca, J. R. S. 2009 Customer satisfaction study via a latent segment model. Journal of Retailing and Consumer Services 16: $352-359$

Gallardo, A., M. D. Bovea, F. J. Colomer, M. Prades, M. Carlos 2010 Comparison of different collection systems for sorted household waste in Spain. Waste Management 30: 2430-2439

González, P. L., B. Adenso 2005 Influence of distance on the motivation and frequency of household recycling. Waste Management 25: 15-23

Greene, W. H., D. A. Hensher 2003 A latent class model for discrete choice analysis: Contrasts with mixed logit. Transportation Research Part B: Methodological 37: 681-698

Hanemann, W. M., B. Kanninen 1999 The statistical analysis of discrete-response CV data. Valuing Environmental Preferences: Theory and practice of the contingent valuation method in the USA, EC, and Developing Countries, 302-441

Hu, W., A. Hünnemeyer, M. Veeman, W. Adamowicz, L. Srivastava 2004 Trading off health, environmental and genetic modification attributes in food. European Review of Agricultural Economics 31: 389-408

Huang, W., J. Wang, X. Dai, M. Li, M.K. Harder 2014 More than financial investment is needed: Food waste recycling pilots in Shanghai, China. Journal of Cleaner Production 67: 107-116

Husaini, I., A. Garg, K.-H. Kim, J. Marchant, S. J. Pollard, R. Smith 2007 European household waste management schemes: Their effectiveness and applicability in England. Resources, Conservation and Recycling 51: 248-263

Jacobsen, H., M. Kristoffersen, D. Tsotsos 2002 Case studies on waste minimisation practices in Europe. European Environment Agency Copenhagen

Jin, J., Z. Wang, S. Ran 2006 Solid waste management in Macao: Practices and challenges. Waste Management 26: 1045-1051

Kamakura, A., M. Wedel 1999 Market Segmentation: Conceptual and Methodological Foundations. Kluwer Academic Press, (New York) pp. 26

Karousakis, K., E. Birol 2008 Investigating household preferences for kerbside recycling services in London: A choice experiment approach. Journal of Environmental Management 88: 1099-1108

Kikulwe, E. M., E. Birol, J. Wesseler, J. Falck 2011 A latent class approach to investigating demand for genetically modified banana in Uganda. Agricultural Economics 42: 547-560

Kontoleon, A., M. Yabe 2006 Market segmentation analysis of preferences for GM derived animal foods in the UK. Journal of Agricultural \& Food Industrial Organization 4

Laurent, A., I. Bakas, J. Clavreul, A. Bernstad, M. Niero, E. Gentil, M. Z. Hauschild, T. H. Christensen 2013 review of LCA stud- ies of solid waste management systems - Part I: Lessons learned and perspectives. Waste Management 34: 573-588

Li, Z., L. Yang, X. Qu, Y. Sui 2009 Municipal solid waste management in Beijing City. Waste Management 29: 2596-2599

Louviere, J. J., D. A. Hensher, J. D. Swait 2000 Stated choice methods: Analysis and applications. Cambridge Univ. Press, Cambridge (UK)

McFadden, D. 1986 The choice theory approach to market research. Marketing science 5: 275-297

Morey, E., J. Thacher, W. Breffle 2006 Using angler characteristics and attitudinal data to identify environmental preference classes: A latent-class model. Environmental and Resource Economics 34: 91-115

Nature, F.o., 2013. A research report on garbage separation of pilot communities in Beijing in 2012 http://www.fon.org.cn/uploads/ attachment/17641370277681.pdf.

Pek, C., O. Jamal 2011 A choice experiment analysis for solid waste disposal option: A case study in Malaysia. Journal of Environmental Management 92: 2993-3001

Qu, X, Z. Li, X. Xie, Y. Sui, L. Yang, Y. Chen 2009 Survey of composition and generation rate of household wastes in Beijing, China. Waste Management 29: 2618-2624

Sakata, Y. 2007 A choice experiment of the residential preference of waste management services - The example of Kagoshima city, Japan. Waste Management 27: 639-644

Shen, J. 2006 A review of stated choice method. International Public Policy Studies 10: 97-121

Shen, J., T. Saijo 2009 Does an energy efficiency label alter consumers' purchasing decisions? A latent class approach based on a stated choice experiment in Shanghai. Journal of Environmental Management 90: 3561-3573

Swait, J. 1994 A structural equation model of latent segmentation and product choice for cross-sectional revealed preference choice data. Journal of Retailing and Consumer Services 1: $77-89$

Swait, J. 2007 Advanced choice models, In: kanninen, B. J. (Ed.), Valuing environmental amenities using stated choice studies. Springer, 229-293

Tadesse, T. 2009 Environmental concern and its implication to household waste separation and disposal: Evidence from Mekelle, Ethiopia. Resources, Conservation and Recycling 53: $183-191$

Tai, J., W. Zhang, Y. Che, D. Feng 2011 Municipal solid waste source-separated collection in China: A comparative analysis. Waste Management, 1673-1682

Victor, O., A. Emmanuel, S. Cecilia 2013 Do economic incentives affect attitudes to solid waste source separation? Evidence from Ghana. Resources, Conservation and Recycling $\mathbf{7 8}$ $115-123$

Yuan Y., M. Yabe 2014a Residents' willingness to pay for household kitchen waste separation services in Haidian and Dongcheng Districts, Beijing City. Environments 1: 190-207

Yuan, Y., M. Yabe 2014b Residents' preferences for household kitchen waste source separation services in Beijing: A choice experiment approach. International journal of environmental research and public health, 12: 176-190

Yang, L., Z. Li, H. Fu 2011 Model of municipal solid waste source separation activity: a case study of Beijing. Journal of the Air \& Waste Management Association, 61: 157-163

Zhou, C., W. Xu, Y. Lan, R. Wang 2014 Community Based Wasteto-Market Model for Sustainable Municipal Solid Waste Management: Closing the Ecological Loop. http://www.athens2014.biowaste.gr/pdf/zhou_et_al.pdf.

Zhuang, Y., S. Wu, Y. Wang, W. Wu, Y. Chen 2008 Source separation of household waste: A case study in China. Waste Management 28: 2022-2030 